\author{
Daniela Tiffany Prado de Carvalho \\ Universidade Federal de Minas Gerais, MG, Brasil \\ Claudia Mayorga \\ Universidade Federal de Minas Gerais, MG, Brasil
}

\title{
Contribuições feministas para os estudos acerca do aprisionamento de mulheres
}

\begin{abstract}
Resumo: Apesar de representar menos de 10\% da população prisional, observa-se um aumento significativo no número de mulheres presas em Minas Gerais. Enquanto, em 2003, contávamos 238 presas, no fim de 2013, já contabilizávamos mais de 2.805 mulheres custodiadas em cadeias, presídios e penitenciárias mineiras. Entretanto, o aprisionamento de mulheres e a participação dessas em atos criminais ainda são recorrentemente analisadas pelo viés do exotismo, como se essa vinculação fosse 'antinatural' para as representantes do sexo feminino, carecendo de explicações que vão do economicismo à moralidade, onde a condição financeira, a parceria amorosa, a sexualidade exacerbada, a falta de caráter e/ou a perversidade aparecem como as explicações predominantes para o envolvimento das mulheres com a criminalidade. Ao nos remetermos à história das punições sob as lentes das teorias feministas, buscamos adentrar um campo de estudos restrito e muito tradicional, ressaltando a importância de analisarmos as instituições prisionais para mulheres a partir das experiências das presas, buscando compreender e questionar os imperativos de seletividade e controle que caracterizam o nosso sistema penal, os quais forjam naturalizações e encobrem processos sócio-históricos que contribuem para a captura de determinadas mulheres e as condenam à privação da liberdade. Palavras-chave: Mulheres; Teoria Feminista; Sistema Prisional
\end{abstract}

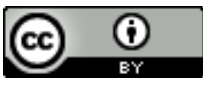

Esta obra está sob licença Creative Commons.

\section{Introdução}

A história das punições é tão antiga quanto a história da humanidade. Diferentes atos e condutas foram sendo tipificadas como crimes ao longo dos séculos, enquanto outros foram perdendo tal conotação. Modificaram-se os tipos penais e as tecnologias de reparação e prevenção ao crime. Modificaram-se, também, aqueles autorizados a determinar e executar a punição, bem como os(as) destinatários(as) das sanções penais. Entretanto, verifica-se 
' Segundo dados coletados diretamente no Sistema Prisional.

\footnotetext{
2 Segundo o Levantamento de Dados para a Política de Melhoria do Encarceramento Feminino, realizado em janeiro de 2014 , a fim de subsidiar a elaboração do Plano Estadual de Apoio às Mulheres Presas e Egressas, de acordo com as Diretrizes do Departamento Penitenciário Nacional/Ministério da Justiça (DEPEN/MJ)
}

certa constância no exercício de regulação da conduta humana, através do estabelecimento de códigos, leis e normatizações. O direito de punir e a aplicação das penas são, sobretudo, um exercício de poder (Michel FOUCAULT, 2008). Tomando como referência os sistemas e as práticas punitivas ao longo dos séculos, identificamos as íntimas articulações entre poder, punição e o direito penal. Quando associamos a essa análise as histórias de mulheres condenadas pela prática de atos considerados criminosos, percebemos que muito pode nos ser revelado sobre poder e sociedade.

Analisando nosso contexto atual, observa-se, nos últimos anos, um crescimento significativo no número de pessoas presas em nosso país. De acordo com os dados do Departamento Penitenciário Nacional (DEPEN), no ano de 2013, a população prisional brasileira era composta por 574.027 presos e presas. Entretanto, se agregarmos a este número o quantitativo de pessoas em cumprimento de prisão domiciliar (regime aberto), ultrapassamos 715.000 detentos, condenados ou provisórios, conforme demonstraram os dados apresentados pelo Conselho Nacional de Justiça (CNJ) em junho de 2014.

Entre os anos de 1990 e 2010 (SISTEMA PENITENCIÁRIO, 201 1), a população prisional brasileira aumentou em $450 \%$, enquanto a média de crescimento da população nacional foi de aproximadamente $26 \%$ nesse mesmo período. Para cada grupo de 100.000 habitantes, estima-se que aproximadamente 280 brasileiros estejam privados de sua liberdade, acusados ou condenados pela prática de atos criminosos. Minas Gerais é o segundo Estado do país em total de presos: há mais de 55.000 pessoas em situação de privação de liberdade (260 presos por grupo de 100.000 mil habitantes) (IBGE, 2013), precedido apenas pelo Estado de São Paulo, que fechou o ano de 2013 com mais de 207.447 pessoas atrás das grades ( 475 presos por 100 mil habitantes).

Em se tratando das mulheres, apesar de representar menos de $10 \%$ do total da população prisional do país, observa-se um crescimento que é proporcionalmente ainda mais significativo, sobretudo a partir do ano de 2003. Contávamos, a essa época, em Minas Gerais, com 238 presas, enquanto que, no fim de 2013 , já contabilizávamos mais de 2.805 mulheres custodiadas em cadeias, presídios e penitenciárias ${ }^{2}$ mineiras. De acordo com o Ministério da Justiça, enquanto a média nacional de crescimento da população prisional feminina foi de $256 \%$ em 12 anos (BRASIL, 2011), identificamos, nesse Estado, um percentual de crescimento de mais de $1.200 \%$ no número de mulheres presas. 
${ }^{3}$ Os dados utilizados nessa análise foram retirados da Relação Geral de Presos que me foi disponibilizada pelo Complexo Penitenciário Feminino Estevão Pinto no dia $13 / 01 / 2014$, realizada com base nas informações cadastradas no INFOPEN. Constavam, nessa relação, as seguintes categorias: duração da pena, estado civil, escolaridade, idade, procedência e tipo de crime.
Entretanto, uma análise mais pormenorizada desses números indica que, para muito além do crescimento desta população prisional, existem certas recorrências no perfil das presas que merecem destaque e atenção. Pesquisa realizada com as presas do Complexo Feminino Estevão Pinto, em Belo Horizonte (Daniela Tiffany Prado de CARVALHO, 2014) revela que são elas, em sua maioria, mulheres com até 30 anos de idade (43\%), não brancas $(66,2 \%)$, solteiras $(66,0 \%)$, procedentes de áreas urbanas $(95 \%)$, com ensino fundamental incompleto (56\%), em cumprimento de sentença condenatória de, em média, até 8 anos, em decorrência, sobretudo, de crimes vinculados ao tráfico de drogas. ${ }^{3} \mathrm{E}$ esse não é apenas um retrato de uma unidade prisional, mas caracteriza o perfil das quase 3.000 mulheres presas em Minas Gerais, no Brasil e em outros países. De acordo com relatório da Organização dos Estados Americanos, o perfil da mulher presa, na atualidade, é: "jovem, mãe solteira, afrodescendente e, na maioria dos casos, condenada por tráfico de drogas ou entorpecentes" (CENTRO PELA JUSTIÇA E PELO DIREITO INTERNACIONAL et al., 2007, p. 15). Em entrevista à Revista Estudos Feministas (2003), Angela DAVIS confirma tal informação, ao relatar que:

Se eu fosse tentar sintetizar as minhas impressões das visitas às prisões ao redor do mundo, e na sua maioria foram visitas a prisões femininas, incluindo três penitenciárias que visitei involuntariamente, teria de dizer que elas são sinistramente parecidas. Sempre me senti como se estivesse no mesmo lugar. Não importa o quão longe eu viajasse através do tempo e do espaço - de 1970 a 2000, e da Casa de Detenção Feminina em Nova lorque (onde eu mesma estive presa) até a prisão feminina em Brasília, Brasil -, não importa a distância, existe uma estranha similaridade nas prisões em geral, e especialmente nas prisões femininas. Essa mesmice das prisões femininas precisa ser avaliada com relação ao quanto é importante para os feminismos desvencilharem-se da noção de que há uma qualidade universal que podemos chamar de mulher. Isso me faz pensar no seu trabalho sobre o desafio de repensarmos as fronteiras entre as ciências sociais e as humanidades, como um meio de reflexão específica sobre as mulheres nas prisões (DAVIS; Gina DENT, 2003, p. 527).

De acordo com Andrei KOERNER (2006), "as condições das prisões correspondem à forma de estruturação das relações sociais sob um aspecto mais geral" (p. 222). Consequentemente, um estudo sobre as prisões é, também, um estudo sobre a sociedade, sobre o poder, sobre os mecanismos de disciplina e de segurança que, em consonância com outros sistemas opressivos,

Estudos Feministas, Florianópolis, 25(1): 99-116, janeiro-abril/2017 101 
perpetuam lógicas e práticas de subordinação, restrições e múltiplas privações. A realização de estudos sobre os estabelecimentos prisionais femininos e o crescente encarceramento de mulheres, orientados por perspectivas feministas, nos possibilitam compreender, a partir de novos pontos de vista, de quais maneiras operam os mecanismos de controle e seletividade penal que capturam determinadas mulheres e subordinam-nas à condição de criminosas e de presas.

Para além de perspectivas que, tradicionalmente, enfatizam os aspectos estruturais dos estabelecimentos prisionais femininos, a suposta criminalidade em decorrência da parceria amorosa e questões relacionadas à maternidade em contexto prisional, ou a elaboração de possíveis 'diagnósticos' sobre fatores que possam explicar a motivação das mulheres para a prática criminal, é importante compreender que algumas características sóciodemográficas comuns a muitas das presas transformam-se em marcadores hierárquicos e discriminatórios, que favorecem processos de criminalização e o aprisionamento de determinadas mulheres, restringindo suas oportunidades de vida e condenando-as para a prisão.

\section{Sobre mulheres, criminalidade e punição}

Apesar da representação numericamente inferior de mulheres no sistema prisional e de uma localização historicamente marginal nos sistemas punitivos, observamos que, sobre as mulheres que ousam cometer práticas tipificadas como criminosas, recai uma dupla punição: as sanções penais previstas nas leis e nos códigos, mas, também, os imperativos das normativas de gênero, com as suas definições e prescrições do que é - ou deveria ser - a Mulher. Da pena capital à privação da liberdade, muitas mulheres foram julgadas pelos seus atos, mas condenadas por suas paixões, por seus instintos, anomalias, enfermidades, inadaptações ou, até mesmo, pela hereditariedade (FOUCAULT, 2004).

Emblemáticas são as histórias das mulheres perseguidas pela Inquisição e condenadas a serem mortas e/ou queimadas em fogueiras, acusadas pela prática de bruxaria. Por não professarem a fé cristã, por serem feias ou demasiadamente belas, as mulheres consideradas bruxas, bem como suas herdeiras, foram consideradas inimigas da Igreja e do Estado. No contexto científico, as diferenças e diversidades entre as mulheres também foram taxadas como anomalias, como indicativos de periculosidade. Cesare LOMBROSO (1871, apud Thais Dumêt FARIA, 2010), importante representante da Criminologia Positivista, empenhou-se na 
classificação das características físicas e traços atávicos que pudessem caracterizar anomalias e anormalidades, identificando os possíveis delinquentes, a fim de defender a sociedade de bem dos degenerados morais ainda não eliminados pela seleção natural. Em se tratando das mulheres, o grau de desenvolvimento dos órgãos genitais, a identificação de uma sexualidade exacerbada, caracterizada pela prática da masturbação e do lesbianismo, serviram como critérios para a classificação dessas em "criminosas natas", criminosas ocasionais, ofensoras histéricas, criminosas de paixão, suicidas, mulheres criminosas lunáticas, epilépticas e/ou moralmente insanas (FARIA, 2010, p. 6072). Seguindo seus passos, Rafael Garófalo, discípulo de Lombroso, em 1879, "atribui a tendência ao crime a tipo de anomalia moral, curável ou incurável" (Tania KOLKER, 2004, p. 178), conferindo relevância ao fator psicológico para o estudo da criminologia.

No início do século XX, tivemos, ainda, as contribuições freudianas para a explicação da criminalidade feminina. Essa seria uma "rebelião contra o natural papel biológico da mulher e evidenciava um 'complexo de masculinidade'" (Don C. GIBBONS, 1977, apud Julita LEMGRUBER, 1979, p. 31). A ausência de sentimentos maternais foi identificada como um importante fator associado à periculosidade feminina, pois seria um indicativo da "inversão de todas as qualidades que em especial caracterizam a mulher normal: reserva, docilidade e apatia sexual" (Manuela Ivone P. da CUNHA, 1994, p. 68). Tais perspectivas, que perpassaram $\circ$ pensamento criminológico até meados do século $X X$, relevavam bases fisiológicas, psicológicas, mas, também, morais, como explicação para a prática de crimes de autoria feminina:

Desregulamentos hormonais, síndromes pré-menstruais (para crimes violentos), desvios sexuais (para prostituição), complexos, neuroses e manias (a compulsividade maníaca para o furto, entre outros), estariam na origem dos motivos que levariam as mulheres a delinquir (CUNHA, 1994, p. 68).

Contrapondo-se às Teorias Clássicas de abordagens biológicas ou psicológicas que tentavam identificar (e imputar) nos indivíduos as características que comprovassem predisposições inatas para o comportamento criminoso, o francês Emile Durkheim desenvolveu uma nova teoria, no fim do século XIX, considerando o crime como um fenômeno sociológico, inerente ao funcionamento de toda e qualquer sociedade e não podendo ser atribuído a qualquer indivíduo em particular (Eduardo Cerqueira BATITUCCI, 1999, p. 12). A partir 
das proposições durkheimneanas, Merton, em meados do século XX, tomando como referência as contradições entre estrutura social e cultura, propôs o estado de anomia social como explicação, do ponto de vista sociológico, para o fenômeno da criminalidade. A incompatibilidade entre os objetivos prescritos culturalmente (sucesso, dinheiro, poder) e os meios institucionais legítimos para a realização dessas aspirações (trabalho e estudo, por exemplo) implicariam uma situação de anomia, da qual poderiam decorrer os atos criminosos (Alessandro BARATTA, 2002). Essa nova teoria considerava que a extrema ênfase na acumulação de riqueza como símbolo de sucesso na nossa sociedade, em contraposição ao acesso limitado aos modos institucionalmente regulados de se adquirir uma fortuna, poderia aumentar a busca de recursos ilegais para o alcance de objetivos socialmente valorizados (BATITUCCI, 1999, p. 18)

Apesar de a vinculação entre criminalidade e pobreza ter sofrido críticas no campo da Sociologia Criminal, essa teoria foi importante para ampliar os debates e estimular desdobramentos teóricos relevantes para a compressão do fenômeno das práticas criminais a partir da segunda metade do século XX. Autores como Otto POLLACK (1978), na década de 50, por exemplo, propõem que as diferenças nas taxas de criminalidade feminina e masculina não deviam se pautar em características que seriam inatas aos homens e às mulheres, pois refletiam, tão somente, as distinções sociais imputadas aos representantes de cada sexo. Dessa maneira, o autor tinha a expectativa de que a promoção da igualdade entre homens e mulheres e a ida delas para o mercado de trabalho poderiam, inclusive, equiparar as taxas de autoria e incidência da criminalidade feminina.

Tal perspectiva orientou um importante estudo brasileiro sobre esta temática, a dissertação de mestrado escrita por Julita LEMGRUBER (1979), posteriormente publicada sob o título: Cemitério dos Vivos: análise sociológica de uma prisão de mulheres, que se tornou um importante referencial para a compreensão dos problemas que perpassam o encarceramento feminino no contexto brasileiro, além de denunciar a precariedade dos estabelecimentos prisionais e a inadequação do sistema quando o que está em questão é a custódia de mulheres. Entretanto, Cunha (2000) se contrapõe à proposição de que a emancipação das mulheres para o mercado de trabalho as teria deixado mais susceptíveis à prática de atos criminais, como uma espécie de "contraefeito" do feminismo. A autora enfatiza que "as mulheres de baixo" sempre investiram na esfera do trabalho, não enquanto ação 


\begin{abstract}
${ }^{4}$ A primeira pesquisa sobre a população prisional feminina em Tires, Portugal, foi realizada em 1987. Dez anos depois, a pesquisadora retornou a esse estabelecimento prisional para analisar, dentre outros fatores, as mudanças ocorridas no perfil sociológico do pessoal penitenciário e das reclusas (CUNHA, 1994, p. 1).
\end{abstract}

emancipatória, digamos, ou contra-hegemônica, mas como condição e exigência de sobrevivência.

Em um estudo comparativo realizado por Cunha (2000) na Penitenciária de Tires, Portugal, a autora demonstra uma alteração significativa no perfil penal das condenadas, no intervalo de 10 anos, entre as décadas de 80 e $90: 4$

\begin{abstract}
Antes podia constatar-se uma relativa diversidade no tipo de crime, ainda que já com uns expressivos $26 \%$ de tráfico de entorpecentes e, por outro lado, uma predominância de crimes contra o patrimônio cheques sem provisão, furto, roubo e burla. Ora, hoje, $76 \%$ das reclusas de Tires estão acusadas ou condenadas por tráfico de entorpecentes, e, das que cometeram crimes contra o patrimônio (18\%), a maioria é tóxicodependente (63\%). Assim sendo, $94 \%$ desta população encontra-se presa por crimes com alguma conexão com a droga (p. 2).
\end{abstract}

De acordo com a autora, tanto a mudança no perfil penal das mulheres presas quanto o crescimento abrupto no número de encarceradas podem ser atribuídos ao fato de o tráfico varejista de drogas ter emergido como uma atividade altamente inclusiva para as mulheres pobres, pela possibilidade de geração de renda através da inserção em "pequenos nichos nos interstícios desta economia", sobretudo, em funções subalternas ou marginais. A maior similaridade no perfil das mulheres presas, quando comparado à população prisional masculina, pode ser atribuída aos tipos de crime que conduzem as mulheres ao cárcere, diferentemente dos homens, em que se observa maior variação nas práticas criminais que acarretam condenação (CUNHA, 2000).

Em outra pesquisa realizada no Brasil e conduzida por Bárbara M. SOARES e lara ILGENFRITZ (2002) com mulheres presas no Rio de Janeiro, os resultados obtidos apresentaram um importante panorama sobre as especificidades de uma instituição prisional feminina, além de alertar para a importância da implementação de uma política penitenciária diferenciada para as mulheres, em âmbito nacional. Entretanto, fazendo uma revisão sobre diferentes estudos e produções recentes sobre mulheres e prisão, observam-se perspectivas recorrentes e uma preocupação quase que predominante: a gestação e o nascimento dos filhos enquanto as mães cumprem suas penas (Daniela VIAFORE, 2005; Marcia de LIMA, 2006; Rosangela Peixoto SANTA RITA, 2006; Vanessa Fusco Nogueira SIMÕ̃ES, 2013).

Há, ainda, outras perspectivas que buscam explicar o crescente aprisionamento feminino a partir da perspectiva da saúde mental, dependência química, análise de comportamentos, escolhas ou fatores sociais ou 
intrapsíquicos das condenadas, conforme podemos observar no trecho abaixo:

As pesquisas descrevem que as presas têm um elevado grau de comorbidade psicopatológica, dependência de substâncias, transtorno de estresse pós-traumático, transtorno de personalidade antissocial e depressão maior. As encarceradas são também mais propensas a terem experiências traumáticas, incluindo abuso físico e sexual precoce. Diversos estudos apontam uma estimativa de que um a dois terços de todas as mulheres encarceradas necessitam de tratamento de saúde mental, aproximadamente um quinto tem uma história de uso de medicação psicotrópica (Daniela Canazaro de MELLO, 2008, p. 45-46).

Encontramos, também, a seguinte explicação para o envolvimento de jovens do sexo feminino com a criminalidade: "condutas criminais podem ser consideradas como expressão de uma relação patológica com o risco" (Patricia CONSTANTINO, 2001, p. 160). A prática criminal seria, então, uma escolha para essas jovens, pautada no

gozo proporcionado pela aventura, pela possibilidade de mudar o que por herança lhes foi reservado, pois as histórias de exclusão dessas jovens nada mais são do que a reedição da vida de seus pais e avós (CONSTANTINO, 2001, p. 61-62).

Para fugirem do fatalismo, elas arriscariam suas vidas no tráfico de drogas, em busca da felicidade fugaz e de prazeres momentâneos, na tentativa de escaparem de uma existência sem expectativas e emoções.

Pesquisa realizada em um contexto escolar, em pleno século XXI, por Mirian ABRAMOVAY e Anna Lúcia CUNHA et al. (2010b), constatou que a conduta violenta por parte das adolescentes é ainda considerada antinatural, por se contrapor à representação hegemônica que se tem sobre "a mulher": seres passivos, frágeis e cândidos. O mesmo "espanto" é identificado em relação às "mudanças radicais" nas práticas sexuais das garotas, que estariam muito mais ousadas. Poderíamos classificar a prática da violência e da sexualidade pelas representantes do sexo feminino como uma "inversão de valores"? Estaríamos diante de novas feminilidades, conforme interrogam as pesquisadoras? Ou essa é apenas mais uma constatação de que a escola, bem como o sistema penal, delimita os campos de aptidões e competências, esquadrilhando identidade e definindo modelos de comportamento pautados em prescrições de feminilidade, masculinidade e sexualidade heterossexual? (ABRAMOVAY E CUNHA, 2010a). 
Herdeiros que somos de perspectivas criminológicas e cientificistas clássicas, positivistas e/ou tradicionais, nos acostumamos a tentar explicar o aprisionamento feminino a partir de definições, muitas vezes estereotipadas ou patologizantes, sobre quem são, de onde vêm e como se comportam as criminosas. Muitas vezes, sem perceber, acabamos reproduzindo discursos e práticas de exclusão, controle e contenção para aquelas que foram historicamente marginalizadas. Ao examinar as pessoas tentando classificálas e predizer seus comportamentos, a Psicologia contribuiu substancialmente para a consolidação de formas maciças de padronização, possibilitando a administração da multiplicidade, a sua organização e a coordenação das trajetórias laterais e horizontais, verticais e piramidais que mantêm as hierarquias que sustentam - e caracterizam - os sistemas disciplinares e, também, os sistemas de segurança pública (FOUCAULT, 2008, p. 17).

\section{O feminismo e as prisões}

As metáforas correlacionadas à visão são caras à teoria feminista: olhar, lentes, ponto de vista etc. Mas não devem se restringir a um só sentido e, sim, orientar o nosso foco de análise para a diversidade e as diferenças. Lançar nossos olhares para o crescente aprisionamento de mulheres é um exercício que nos possibilita compreender as múltiplas facetas e intersecções e opressões que, historicamente, recaem sobre essas, sobretudo quando são pobres, não brancas e homossexuais. Porém, ao focar nas experiências marginalizadas de mulheres presas, não queremos restringir, mas ampliar nossas compreensões sobre as reinvenções do poder de punir e oprimir. Uma análise crítica das instituições prisionais de mulheres a partir de um ponto de vista feminista pode contribuir para uma compreensão menos parcial das prisões contemporâneas, possibilitando reformulações no quadro teórico dos estudos prisionais e ampliando o debate sobre reclusão, exclusão e controle social. Angela Davis (2003) indica a amplitude desse tema e as dimensões dessa luta:

Qualquer estudo convencional das ciências sociais sobre mulheres prisioneiras vai lhe apresentar uma prisioneira típica - geralmente caracterizada como "mãe", com um nível de escolaridade relativamente baixo e que é também viciada em drogas. Nós sabemos que, quando vamos a prisões femininas em um país europeu, descobrimos - como no caso das masculinas - um número bastante desproporcional de mulheres imigrantes, cidadãs ilegais, africanas, asiáticas e latinas. Mas [...], isso não é o suficiente. Também temos de considerar o papel que a 
criminologia e o estudo da punição têm tido na criação dessas impressionantes similaridades, não só nas populações, mas nos métodos de controle, modelos arquitetônicos e práticas de custódia originadas da psicologia do criminoso, que é generalizada ao redor do mundo. Em outras palavras, a instituição da prisão e seu uso discursivo produzem o tipo de prisioneiro que, por sua vez, justifica a expansão das prisões (DAVIS; DENT, 2003, p. 527).

Em concordância com a autora, consideramos que essa "sinistra" similaridade entre as instituições prisionais e as características de suas cativas pode ser um importante indicativo da utilização da prisão enquanto instituição historicamente contingente que revela as intersecções entre sistemas punitivos, econômicos, sexistas e racistas na atualidade, em diferentes lugares do mundo (DAVIS; DENT, 2003, p. 526). O estudo sobre o crescente aprisionamento de mulheres é um campo de reflexões e desafios propício ao trabalho das intelectuais feministas que, interpelando os limites do(s) feminismo(s), revelaram as intersecções dos sistemas opressivos, desbravando terrenos para novas lutas (DAVIS; DENT, 2003, p. 20).

Em interlocução com as teóricas que interpelaram o feminismo e em diálogo com as vozes contidas e desautorizadas de mulheres marginalizadas, queremos desvendar as artimanhas dos sistemas sexistas, racistas, capitalistas, colonialistas e punitivos que se intersectam, se sobrepõem e se potencializam, forjando teias e naturalizações que capturam determinadas mulheres. Ao nos remetermos à história das prisões, tomando como referência as experiências das mulheres presas, nos inserimos nesse campo de estudos, problematizando, inclusive, se a persistência de uma noção muito restrita e específica de Mulher estaria ainda subsidiando o direito de punir práticas e comportamentos definidos como inadequados para aquelas que ainda são tidas como representantes de um determinado sexo, condenando-as às penas privativas de liberdade.

Jogando luz às prescrições e às terapêuticas penais historicamente prescritas para as mulheres, podemos, também, identificar a estreita vinculação entre os estabelecimentos prisionais femininos e a ideologia de gênero que se manifesta em elementos materiais, organizacionais e simbólicos identificáveis nessas instituições, operando através de tecnologias (Teresa de LAURETIS, 1994) ou se reproduzindo quase que por um efeito inercial (CUNHA, 1994). A criminologia feminista explicita que a tentativa de "restabelecer a mulher em seu papel social de mãe, esposa e guarda do lar e de fazê-la aderir aos 
valores da classe média" (Olga ESPINOZA, 2002) caracteriza o sistema penal como mais uma instância onde se reproduzem e intensificam as condições de opressão sobre as mulheres, por meio da imposição de padrões de normalidade. O controle penal seria, portanto, uma instância suprema para a correção de condutas que não foram devidamente reguladas pela família, escola e outros mecanismos informais que operam socialmente, reproduzindo as diferenças de gênero e reforçando as estruturas sociais discriminatórias contra a mulher, a partir da ação articulada de sistemas de opressão.

Queremos, também, problematizar as noções restritas de gênero, interpelando a própria concepção da existência da Mulher, enquanto um ser, uma identidade ou uma categoria universal (Claudia MAYORGA; Alba COURA; Nerea MIRALLES; Viviane Martins CUNHA, 2013). Ao longo dos anos, novas interpretações em relação a Gênero, enquanto um conceito ou categoria analítica, foram se desenvolvendo, introduzindo experiências concretas de mulheres reais em diferentes contextos de poder e desigualdade (Karla Galvão ADRIÃO; Maria Juracy Filgueiras TONELI, 2008). Decorrentes de múltiplas reivindicações pelo reconhecimento da diversidade de(os) sujeitos das teorias e políticas feministas, os novos debates e produções defendiam a importância da admissão de que são múltiplos os feminismos, porque diferentes são as disputas e as lutas necessárias para o enfrentamento às desigualdades a que estão submetidas as mulheres (Avtar BRAH, 2006).

Conforme nos aponta Sandra AZERÊDO (1994), é fundamental que estejamos atentos para a necessidade de se complexificar a categoria Gênero - historicizá-la e politizá-la - por meio da superação da ideia de que as mulheres compartilham as mesmas experiências de subordinação, pelo simples fato de serem mulheres (AZERÊDO, 1994), como se essa fosse uma identidade primária que lhes garantisse um caráter de coletividade (Adriana PISCITELLI, 1998). Quando a categoria gênero obscurece todas as outras - raça, classe, nacionalidade -, ela se torna uma identidade globalizante e central, perdendo a sua potência "tanto como categoria analítica, quanto como uma das formas que relações de opressão assumem numa sociedade capitalista, racista e colonialista" (AZERÊDO, 1994, p. 207) como a nossa.

As feministas negras, latinas e pós-coloniais contribuíram significativamente para a ampliação das perspectivas sobre as múltiplas facetas da opressão que é experienciada em distintas relações de poder. Contestando o enfrentamento ao patriarcado como a instância máxima de opressão vivenciada pelas mulheres em relação aos 
homens, emergiram as reivindicações pelo reconhecimento de que há, também, uma multiplicidade de experiências possíveis para as mulheres, expressando a artificialidade de uma identidade essencialista, que tentava limitá-las a uma categoria universalizante: A Mulher.

Analisar e compreender o crescente encarceramento feminino a partir de uma perspectiva feminista pode nos permitir compreender os imperativos de seletividade e controle que caracterizam o nosso sistema penal, forjando naturalizações e encobrindo processos sócio-históricos que contribuem para o encarceramento de determinadas mulheres, sem, entretanto, restringir-se a elas. Nesse contexto, podemos afirmar que a teoria feminista não é uma teoria sobre as mulheres; é uma teoria sobre a sociedade a partir das experiências de mulheres. Em tais experiências, é possível identificarmos os efeitos das relações de poder, sustentadas por visões e lógicas masculinas, classistas, racistas e sexistas e que são produtoras de subjetividades (Ochy CURIEL, 2007), contribuindo para o aprisionamento de um número cada vez maior de determinadas mulheres.

O enfoque epistemológico que orienta a teoria feminista parte das experiências concretas das mulheres enquanto conhecedoras situadas (CURIEL, 2007), a fim de compreender de que maneira as opressões (racial, sexual, heterossexual e classista) criam diferentes condições de vida, em lugares e contextos específicos. Foi exatamente "a partir da experiência de opressão e discriminação das mulheres e dos desejos de condições sociais emancipatórias, livres de dominação, discriminação e exclusão" (MAYORGA et al., 2016), que as próprias mulheres, feministas ou não, foram travando suas batalhas e se fortalecendo para novas lutas, enfrentamentos e reivindicações. O conhecimento resultante dessa prática, percebendo-se limitado e instável, recusa-se a ser limitante e determinante (Sandra HARDING, 2004), estimulando outras práticas, novas produções, novos olhares e o reconhecimento de outros saberes, muitas vezes marginalizados. A partir do fortalecimento das teorias $e$ críticas feministas, podemos afirmar a importância das diversidades situadas, encarnadas e consideradas, a fim de que tenhamos possibilidades ampliadas de futuro, experienciadas em/a partir de múltiplos corpos, significados e sentidos (Donna HARAWAY, 1995).

\section{Considerações finais}

O crescimento da população prisional feminina nos últimos anos, proporcionalmente superior ao crescimento da população prisional masculina, merece atenção, 
preocupação e análises. Apesar de representar menos de $10 \%$ de todo o contingente de presos em nosso país, essa crescente parcela de mulheres em situação de prisão indica que, para além das reivindicações em prol da conquista de igualdade entre homens e mulheres, precisamos avançar muito nos debates acerca da garantia da liberdade para mulheres que ainda se encontram subordinadas a contextos de múltiplas privações e opressões. E em um contexto como o prisional, precisamos questionar se o discurso da igualdade não foi cooptado, inclusive, para que não sejam garantidas às mulheres presas melhores condições para o cumprimento de suas penas.

Entretanto, precisamos ficar atentos para que o avanço na garantia de direitos para as mulheres presas não se restrinja à melhoria das condições para permanência do cuidado com os filhos nos estabelecimentos prisionais e nem em outras medidas originárias de concepções essencialistas sobre a Mulher (mãe, esposa e guarda do lar), bem como ações que privilegiam o culto a determinados modelos padronizados de beleza como suposto sinônimo de autoestima e a imposição de padrões de moralidade e sexualidade heteronormativa. Mas será apenas a partir da leitura dessa complexa realidade, a partir de outras perspectivas e de outras lentes analíticas, que poderemos introduzir novos elementos neste debate?

Cunha (2011) ressalta, inclusive, que restringir o estudo de prisões de mulheres a uma perspectiva de gênero tende a prejudicar, equivocadamente, o avanço das produções científicas, o reconhecimento da abrangência e relevância do tema, reforçando perspectivas biológicas e psicologizantes, muitas vezes redutoras e reprodutoras de distorções que encobrem realidades complexas. Estaríamos incorrendo no risco de, neste contexto, sermos cooptadas por uma perspectiva simplista da noção de gênero que transformaria os estudos sobre aprisionamento feminino em um problema restrito às mulheres. Entretanto, quando nós, pesquisadoras feministas, nos posicionamos neste campo que ainda é predominantemente masculino, empenhadas em ampliar os debates e as reflexões sobre a problemática do encarceramento feminino, podemos contribuir para a formulação de novas perguntas, outras reflexões e mais debates sobre esse tema.

As críticas direcionadas ao modelo científico tradicional denunciaram que muitos dos pressupostos de cientificidade - perspectiva de isenção, objetividade e imparcialidade - deixaram as mulheres às margens da produção de conhecimento, tanto como pesquisadoras quanto como sujeitos das pesquisas. As diferenças entre os números de homens e mulheres presos não podem persistir 
como argumento hegemônico que estabelece a reclusão masculina como o paradigma universalizante para a produção de conhecimento sobre as prisões no século XIX, adiando necessárias reformulações nas políticas penitenciárias e de segurança pública (CUNHA, 2011). Precisamos interpelar os números e estatísticas que acabam relegando a questão do aprisionamento feminino como sendo um problema de ordem inferior para o contexto da segurança pública e da gestão penitenciária, para que possamos avançar na compreensão de que a privação da liberdade é um recurso extremo de exercício de controle e de poder sobre determinadas mulheres, que, tantas vezes alijadas do acesso aos seus direitos mais fundamentais, acabam subordinadas ao direito de punir do Estado.

O estudo das prisões a partir de uma perspectiva feminista não releva apenas uma escolha teórica, mas explicita um posicionamento ético, acadêmico e político. Ao desenvolver pesquisas com mulheres em situação de prisão a partir de uma perspectiva feminista, poderemos enfrentar a invisibilidade que recai sobre o aprisionamento feminino e avançar na compreensão, a partir da experiência das presas, sobre como operam diferentes mecanismos de opressão que acabam por culminar na privação da liberdade. A luta pela superação das opressões é uma batalha cotidiana por um conceito mais ampliado de justiça e pela redução das desigualdades entre os homens, entre homens e mulheres, mas, também, entre as mulheres. E é também uma luta pela liberdade de inúmeras mulheres condenadas em contextos de reiteradas privações, opressões e violências. Esta é uma luta feminista, é um grande desafio para todas nós!

\section{Referências}

ABRAMOVAY, Mirian; CUNHA, Anna Lúcia et al. Gangues, gênero e juventudes: donas de rocha e sujeitos cabulosos. Brasília: Secretaria de Direitos Humanos, $2010 a$.

ABRAMOVAY, Mirian; CUNHA, Anna Lúcia. Masculinidades, feminilidades e violência no cotidiano das escolas, 2010b. Disponível em: http://seer.uniritter.edu.br/ index.php/educacaoecidadania/article/view/139/59. Acesso em: 12/01/2013.

ADRIÃO, Karla Galvão \& TONELI, Maria Juracy Filgueiras. "Por uma política de acesso aos direitos das mulheres: sujeitos feministas em disputa no contexto brasileiro". Psicologia \& Sociedade, v. 20, n. 3, 2008. Disponível em: http:// www.scielo.br/scielo.php?script =sci_arttext\&pid=S010271822008000300017 . Acesso em: 30/03/2013. 
AZERÊDO, Sandra. "Teorizando sobre gênero e relações raciais". Revista Estudos Feministas, Florianópolis, n. e., p. 203-216, 1994.

BARATTA, Alessandro. Criminologia crítica e crítica do Direito Penal: introdução à sociologia do direito penal. 3.ed. Rio de Janeiro: Revan; Instituto Carioca de Criminologia, 2002.

BATITUCCl, Eduardo Cerqueira. Aspectos da abordagem sociológica do crime e da prisão. Belo Horizonte: Fundação João Pinheiro, 1999.

BRAH, Avtar. "Diferença, diversidade, diferenciação". Cadernos Pagu, n. 26, p. 329-376, 2006. Disponível em: http://www.scielo.br/pdf/cpa/n26/30396.pdf. Acesso em: 15/10/2012.

BRASIL. Ministério da Justiça. Departamento Penitenciário Nacional. Sistema Nacional de Informação Penitenciária - InfoPen. Relatórios Estatísticos-Analíticos do Sistema Prisional de cada Estado da Federação, 2011 . Disponível em: http://www.justica.gov.br/seus-direitos/politica-penal/ transparencia-institucional/estatisticas-prisional/ relatorios-estatisticos-analiticos-do-sistema-prisional.

CARVALHO, Daniela Tiffany Prado. Nas entre-falhas da linha vida: experiências de gênero, opressões e liberdade em uma Prisão Feminina, 2014. Dissertação (Mestrado em Psicologia Social), Universidade Federal de Minas Gerais, Minas Gerais.

CENTRO PELA JUSTIÇA E PELO DIREITO INTERNACIONAL - CEJIL et al. Relatório sobre mulheres encarceradas no Brasil. Brasília, 2007. Disponível em: http://carceraria.org.br/wpcontent/uploads/2013/02/Relato\%CC\%8 1 rio-para-OEAsobre-Mulheres-Encarceradas-no-Brasil-2007.pdf. Acesso em: 12/01/2013.

CONSTANTINO, Patricia. Entre as escolhas e os riscos possíveis: a inserção das jovens no tráfico de drogas, 2001. Dissertação (Mestrado), Escola Nacional de Saúde Pública, Fundação Oswaldo Cruz, Rio de Janeiro. Disponível em: http://teses.icict.fiocruz.br/pdf/ constantinpm.pdf. Acesso em: 25/07/2012.

CUNHA, Manuela Ivone P. da. Malhas que a reclusão tece: questões de identidade numa prisão feminina. Lisboa: Gabinete de Estudos Jurídico-Sociais do Centro de Estudos Judiciários, 1994. Disponível em: // repositorium.sdum.uminho.pt/bitstream/1 822/5237/4/ Malhas\%20que\%20a\%2Oreclus\%25C3\%25A30\%2Otece.pdf. Acesso em: 30/01/2013.

. "A criminalidade (re)vista e comentada a partir da prisão". In: MARTINS, Moisés de Lemos (Coord.). Crime e castigo: práticas e discursos. Braga: Instituto de Ciências Sociais da Universidade do Minho, 2000. Disponível em: 
http://repositorium.sdum.uminho.pt/bitstream/1822/5227/3/ A\%20criminalidade\%20\%28re\%29vista\%20e\%20comentada\% 20a\%20partir\%20da\%20pris\%C3\%A3o.pdf. Acesso em: 20/04/ 2013.

"Agendas públicas, agendas de investigação e a prisão como objecto etnográfico". In: PORTELA, José; SACRAMENTO, Octávio; SILVA, Pedro Gabriel (Orgs.). Etnografia e intervenção social: por uma práxis reflexiva. Lisboa: Colibri, 2011 . p. 48-60.

CURIEL, Ochy. "La crítica poscolonial desde las prácticas políticas del feminismo, antirracista". Revista Nómadas, v. 26 , n. 4, p. 92-101, 2007 .

DAVIS, Angela; DENT, Gina. "A prisão como fronteira: uma conversa sobre gênero, globalização e punição". Revista Estudos Feministas, Florianópolis, v. 11, n. 2, 2003. Disponível em: http://www.scielo.br/ scielo.php?script=sci_arttext\&pid=s0104$026 \times 2003000200011 \& \operatorname{lng}=$ pt\&nrm $=$ iso\&tlng $=$ pt. Acesso em: 10/07/2012.

ESPINOZA, Olga. "A prisão feminina desde um olhar da criminologia feminista". Revista Transdisciplinar de Ciências Penitenciárias, v. 1, n. 1, p. 35-59, jan.-dez. 2002. Disponível em: http://pt.scribd.com/doc/98749865/APrisao-Feminina-Desde-Um-Olhar-CriminologiaFeminista. Acesso em: 03/02/2012.

FARIA, Thaís Dumêt. "A mulher e a criminologia: relações e paralelos entre a história da criminologia e a história da mulher no Brasil". In: XIX ENCONTRO NACIONAL DO COMPEDI. Fortaleza, CE, 2010, p. 6067-6076. Disponível em: http://www.conpedi.org.br/manaus/arquivos/anais/ fortaleza/3310.pdf. Acesso em: 10/05/2012.

FOUCAULT, Michel. Vigiar e punir: nascimento da prisão. 28.ed. Petrópolis: Vozes, 2004.

Segurança, território, população. São Paulo: Martins Fontes, 2008.

HARAWAY, Donna. "Saberes localizados: a questão da ciência para o feminismo e o privilégio da perspectiva parcial". Cadernos Pagu, n. 5, p. 7-41, 1995.

HARDING, Sandra. The feminist standpoint theory reader: intellectual and political controversies. Oxford: Psychology Press, 2004.

KOERNER, Andrei. "Punição, disciplina e pensamento penal no Brasil do Século XIX". Lua Nova, n. 68, p. 205-242, 2006. Disponível em: http://www.scielo.br/pdf/ln/n68/ a08n68.pdf. Acesso em: 12/03/2013.

IBGE. Minas Gerais, 2013. Disponível em: http:// www.ibge.gov.br/estadosat/perfil.php?sigla=mg.

KOLKER, Tania. "A atuação do psicólogo no sistema prisional". In: GONÇALVES, Hebe Signorini; BRANDÃO,

114 Estudos Feministas, Florianópolis, 25(1): 99-116, janeiro-abril/2017 
Eduardo Ponte (Orgs.). Psicologia Jurídica no Brasil. Rio de Janeiro: Nau Editora, 2004.

LAURETIS, Teresa de. "A tecnologia do gênero". In: HOLLANDA, Heloisa Buarque de. Tendências e impasses: o feminismo como crítica da cultura. Rio de Janeiro: Rocco, 1994.

LEMGRUBER, Julita. Cemitério dos vivos, 1979. Dissertação (Mestrado), Instituto de Pesquisas Universitárias do Rio de Janeiro, Rio de Janeiro.

LIMA, Marcia de. Da visita íntima à intimidade da visita: a mulher no sistema prisional, 2006. Dissertação (Mestrado), Faculdade de Saúde Pública, USP, São Paulo. Disponível em: http://www.teses.usp.br/teses/disponiveis/ 6/6136/tde-24032008-085201/pt-br.php. Acesso em: 12/ $06 / 2012$

MAYORGA, C. et al. "Gênero, feminismo, psicologia social no Brasil: Análise da Revista Psicologia e Sociedade (19962010)". Revista Psicologia \& Sociedade, v. 28, n. 3, p. 589-603, 2016.

MAYORGA, Claudia; COURA, Alba; MIRALLES, Nerea; CUNHA, Vivane Martins. "As críticas ao gênero e a pluralização do feminismo: colonialismo, racismo e política heterossexual". Revista Estudos Feministas, v. 21, n. 2, 2013. Disponível em: http://www.scielo.br/scielo.php?pid=SO1 04-026X2013000200003\&script=sci_arttext. Acesso em: $30 / 03 / 2014$.

MELLO, Daniela Canazaro de. Quem são as mulheres encarceradas? 2008. Dissertação (Mestrado), Pontifícia Universidade Católica do Rio Grande do Sul, Porto Alegre.

PISCITELLI, Adriana. "Recriando a categoria mulher?". In: ALGRANTI, Leila Mezan (Org.). A prática feminista e o conceito de gênero. Campinas: IFCH/UNICAMP, 1998. p. 7-42.

POLÍTICA Nacional de Atenção às Mulheres em Situação de Privação de Liberdade e Egressas do Sistema Prisional. Documento Basilar para elaboração da Portaria Interministerial MJ/SPM n² 210/2014. Disponível em: http:/ /www.justica.gov.br/seus-direitos/politica-penal/politicas2/mulheres-1/anexos-projeto-mulheres/doc-basilarpolitica-nacional-versao-final.pdf.

POLLACK, Otto. The Criminality of Woman. Westport: Greenwod Press, 1978.

SANTA RITA, Rosangela Peixoto. Mães e crianças atrás das grades: em questão o princípio da dignidade da pessoa humana, 2006. Dissertação (Mestrado), Universidade de Brasília, Brasília.

SIMÕES, Vanessa Fusco Nogueira. Filhos do cárcere: limites e possibilidades de garantir direitos fundamentais dos filhos das mulheres privadas de liberdade no Brasil. Porto Alegre: Núria Fabris, 2013. 
SISTEMA Penitenciário. Resumos Jurídicos, 27/04/2011. Disponível em: https://permissavenia.wordpress.com/ 201 1/04/27/sistema-penitenciario-pesquisa/.

SOARES, Bárbara Musumeci; ILGENFRITZ, lara. Prisioneiras: vida e violência atrás das grades. Rio de Janeiro: Garamond, 2002.

VIAFORE, Daniela. "A gravidez no cárcere brasileiro: uma análise da Penitenciária Feminina Madre Pelletier". Direito \& Justiça, v. 31, n. 2, p. 91-108, 2005.

[Recebido em 08/01/2015, reapresentado em $17 / 05 / 2016$ e aceito para publicação em 23/06/2016]

\section{Feminist Contributions to Studies on Women's Imprisonment}

Abstract: Despite representing less than $10 \%$ of the prison population, there is a significant increase in the number of women prisoners in Minas Gerais. While in 2003 we had 238 women arrested, by the end of 2013 we already accounted more than 2,805 women in custody in Minas chains, prisons and penitentiaries. However, the imprisonment of women and their participation in criminal acts are still recurrently analyzed from the perspective of exoticism, as if this link was 'unnatural' for female representatives, with explanations ranging from economism and morality, where the financial situation, loving partnership, exacerbated sexuality, lack of character and / or wickedness appear as the predominant explanation for women's involvement in crime. As we go back in the history of punishments under the lens of feminist theories, we enter in a restricted and very traditional field of studies, emphasizing the importance of analyzing the women's prisons from the prisoners' experiences, seeking to understand and question the selectivity and control requirements that characterize our penal system, forging naturalization and covering sociohistorical processes that contribute to the capture of certain women and condemn them to deprivation of liberty.

Key words: Women; Feminist Theory; Prison System

Daniela Tiffany Prado de Carvalho (tiffanybhz@gmail.com). Mestre em Psicologia Social pela Universidade Federal de Minas Gerais.

Claudia Mayorga (mayorga.claudia@gmail.com). Doutora em Psicologia Social pela Universidade Complutense de Madri, professora do Programa de Pós-Graduação em Psicologia da UFMG e coordenadora do Núcleo Conexões de Saberes na UFMG. 